\title{
Patrimonio edificado de propiedad privada: relación compleja y contradictoria entre lo público y lo privado en el Centro Histórico de Morelia
}

\author{
Eugenio Mercado López
}

\section{Introducción}

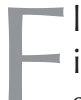
I patrimonio cultural de México está constituido por bienes tangibles e - intangibles, muebles o inmuebles, tanto públicos como privados, que - son dignos de conservarse por sus valores históricos, artísticos, técnicos, científicos o tradicionales. El Estado mexicano otorga especial atención a los espacios y edificios públicos, en tanto que los de propiedad privada frecuentemente se transforman y destruyen, problema que se presenta en diversas ciudades, incluso en sitios considerados Patrimonio Mundial.

La conservación del patrimonio edificado de propiedad privada se inscribe en la dicotomía de lo público y lo privado, al incluir bienes que, inmersos en el mercado inmobiliario, a la vez se consideran un bien público, lo cual, aunado a su significado como elemento de identidad y cohesión social, y generador de beneficios económicos, ha justificado la intervención del Estado, no siempre exitosa, para su conservación y aprovechamiento.

En México la limitación de estudios acerca del patrimonio edificado de propiedad privada, así como los reducidos efectos de las políticas públicas instrumentadas para su protección, son un vacío que el presente trabajo pretende ayudar a subsanar, contribuyendo con el conocimiento de los problemas urbanos vinculados a la conservación de monumentos y centros históricos del país, específicamente el de Morelia, Michoacán.

\section{Metodología}

Se analizó el proceso de conservación y transformación del patrimonio edificado en el Centro Histórico de Morelia, teniendo como fuentes de información los monumentos históricos de propiedad privada, los planes parciales de desarrollo urbano y la planimetría urbana. Se identificaron los usos del suelo, el estado de conservación y mantenimiento, el acceso a inmuebles, sus alteraciones y deterioros, comparando los resultados de un estudio de campo efectuado en el 2007, con estudios previos realizados por Ramírez (1981 y 1985), así como con los datos contenidos en el Programa Parcial del Centro Histórico de Morelia (Ayuntamiento de Morelia 2001) y el Catálogo de Monumentos Históricos del INAH (2003). El análisis incluyó el proceso de gestión del 
sitio, la actuación de agentes urbanos, las políticas públicas y sus efectos en los inmuebles patrimoniales privados.

\section{Las contradicciones y complejidades de un concepto}

Propiedad privada y patrimonio edificado son conceptos que surgieron de ámbitos divergentes. El Código Napoleónico consagró la propiedad como un derecho inherente al hombre y objeto de protección irrestricta de toda injerencia del poder público (Moisset de Espanés 1966). Patrimonio cultural, por su parte, es un término contemporáneo derivado del concepto de monumento —nuevas visiones cerrarían la brecha entre estos dos conceptos-, el cual se refería originalmente a una marca pública destinada a transmitir la memoria de algún personaje o de una acción célebre (Debray 1999:15) y que era ajena al ámbito de lo privado. A principios del siglo xx, Duguit enfrentó al sistema liberal, al proponer que la propiedad no es el derecho subjetivo del propietario, sino una función social del tenedor de la riqueza, paradigma que permitió compatibilizar el ascenso del Estado Nacional y la persistencia de la propiedad privada, justificó las restricciones a esta última e hizo posible compaginar la intervención del Estado en la economía que regula la propiedad con los intereses de aquellos que la ejercen (Azuela 1989:2627). El concepto de monumento también evolucionó y ha sido suplido paulatinamente por el de patrimonio cultural, concepto abstracto, general y amplio, pero ajeno a las connotaciones ideológicas y a los intereses políticos, que designa el conjunto de bienes valiosos para la humanidad, cuya diversidad ha requerido precisar diversas categorías, como es el caso del patrimonio edificado, entendido como el conjunto de espacios urbanos y arquitectónicos de valor para una comunidad.

El concepto de la propiedad como función social fue retomado por la legislación mexicana del siglo $\mathrm{xx}$, que dejó atrás los postulados liberales del siglo anterior e hizo posible la intervención pública para la protección, independientemente de su régimen de propiedad, de los monumentos históricos y artísticos, cuya función social se especificó en la iniciativa de creación del Instituto Nacional de Antropología e Historia (INAH) como instrumento para consolidar un proyecto de homogeneización cultural e identidad nacional con función científica, para el conocimiento del pasado, y económica, mediante su aprovechamiento a través del turismo (Olivé 1988:368369).

La protección del patrimonio edificado en México, de competencia federal, tiene su principio jurídico en la Constitución Política del país que, en sus artículos $27^{\circ}, 73^{\circ}$ y $115^{\circ}$ fracción IV, señala las bases legales de la propiedad nacional y la regulación de la propiedad privada, así como los fundamentos para la ordenación y regulación de los asentamientos humanos. En esta última materia, su ley general otorga atribuciones a los muni- cipios en materia de desarrollo urbano y expone, en el artículo $5^{\circ}$ fracción VII, la utilidad pública de la protección del patrimonio cultural de los centros de población. La Ley Federal de Monumentos y Zonas Arqueológicos, Artísticos e Históricos, de 1972, incluye restricciones a los propietarios de inmuebles artísticos e históricos, imponiéndoles la obligación de su conservación, así como de solicitar autorización a las autoridades federales competentes para realizar cualquier intervención en sus propiedades; para los inmuebles dentro de la delimitación de las zonas de monumentos históricos o artísticos, la protección federal también contiene la regulación de intervenciones en espacios públicos e inmuebles de propiedad pública y privada.

Pese al interés público manifestado en la legislación, el Estado mexicano no asume los costos de la conservación del patrimonio edificado privado, con frecuencia ignorado en los programas oficiales de los sitios históricos. Como en este tipo de patrimonio subyace la naturaleza de la propiedad privada vinculada a la comercialización y a la acumulación de riqueza, en su valoración y conservación confluyen aspectos funcionales, sociales, simbólicos, políticos, económicos o urbanísticos.

La permanencia de espacios y edificios antiguos, ya que se relaciona con su capacidad para contener funciones distintas de aquellas para las cuales fueron construidos, se explica no sólo por razones puramente funcionales y de economía de los recursos, sino aun a falta de éstos o de normas para su protección, e independientemente de sus valores estéticos. Asimismo, la valoración del tejido edificado antiguo como configurador de la forma histórica de la ciudad se complementa, frente a los intereses que se benefician de su destrucción, con una valoración económica que también representa una motivación para su conservación (De las Rivas 1998:211).

Los diferentes criterios y el variable interés de grupos o personas por conservar objetos, lugares y expresiones culturales son resultado, como construcción social, de una participación diferenciada en el proceso de selección y apropiación de esos bienes. Esa selección es creadora de valor simbólico y político, pero también económico, ya que dichos bienes están sujetos a las normas del mercado (Rosas 1996), ese mecanismo racional e impersonal que rige la oferta y la demanda y busca el máximo beneficio monetario. De ahí que no sea posible pretender que los bienes privados se encuentren disponibles para el disfrute universal: el análisis económico visualiza los bienes culturales como objetos escasos por su rareza o antigüedad, y el ideal del libre mercado es que la escasez se resuelva mediante mecanismos de precio, oferta-demanda y una regulación por parte del gobierno. No obstante, no se puede asignar un precio a los valores religiosos, estéticos, culturales o simbólicos vinculados a los bienes culturales, sin demeritar su rico significado (Mason 1999:10).

Además, ya que los mercados no pueden proveer ciertas mercancías públicas —-fenómeno denominado falla 
del mercado-, la acción colectiva se encarga de disponer de ellos. Así, en el caso del patrimonio cultural se reconoce que dicha falla es la regla, no la excepción, lo cual implica la necesidad de una intervención pública constante; por ello, la economía estudia los procedimientos para su cuidado, conservación y disposición por parte de la sociedad —centrándose en la actuación de los gobiernos a través de las políticas públicas-, cuando los mercado fallan (Mason 1999:9). El acceso a los bienes culturales, lo mismo que cualquier mercancía, requiere que exista un acervo, su disponibilidad para el consumo y el consumo en sí mismo; el valor de esos bienes se incrementa cuando es posible su uso o goce conjunto, por lo cual las actividades de restauración son indispensables para su disponibilidad como consumo individual o comunitario, la apreciación o la investigación (cfr. Krebs \& Schmidt-Hebbel 2002: 212-213). El consumo público y el consumo privado presentan diferencias y particularidades, ya que el primero es realizado por un gran número de individuos en forma más o menos simultánea sin rivalidad o exclusión plena, en tanto que el segundo se realiza por un individuo con exclusión o rivalidad respecto del consumo de otros; desde esta perspectiva, los bienes culturales privados son bienes intermedios, esto es, se encuentran entre los casos opuestos de bienes de consumo exclusivamente privado y bienes públicos puros, cuyo consumo es de cero rivalidad o exclusión (Krebs y Schmidt-Hebbel 2002:213).

Por otra parte, las denominadas externalidades o efectos de filtración, que inciden en la disponibilidad y el consumo de los bienes culturales, se presentan cuando los actos de grupos o personas imponen un costo o brindan un beneficio a terceras partes. En el caso del patrimonio cultural se han identificado como externalidades la valoración social, la asignación de un precio a los valores sociales, las ineficiencias de la propiedad privada y las políticas públicas (Krebs y Schmidt-Hebbel 2002:213-215).

Como parte de la ciudad, el patrimonio edificado configura zonas urbanas de carácter histórico que, en muchos casos, aún conservan su calidad como centros urbanos generadores, concentradores y conductores de las actividades económicas a escala local y regional (Hernández 2006). Por lo anterior, los procesos de conservación del patrimonio edificado no se limitan a mantener las características de los inmuebles, sino, más allá, a lograr su vigencia funcional y económica, de modo que su protección no tiene el objetivo único de presentarlo para el goce comunitario, sino también el de insertarlo en las formas de producción establecidas en el ordenamiento territorial. El de patrimonio edificado es un concepto que nace y se sustenta en lo público, por lo cual corresponde a este ámbito establecer condiciones propicias para que los inmuebles de propiedad privada mantengan esa múltiple vigencia que garantice su conservación. Desde estos supuestos, se analizan en seguida los efectos de la actuación pública en el Centro Histórico de Morelia.

\section{Resultados}

Con la inclusión del Centro Histórico de Morelia en la Lista del Patrimonio Mundial, en 1991, las políticas públicas enfatizaron tres vertientes: un cuerpo legal que norma las intervenciones en los inmuebles y acota los derechos de los propietarios; la inversión pública en obras de imagen urbana en espacios públicos y edificios emblemáticos, así como una gestión del patrimonio orientada a la especialización turística. Como acciones concretas, se descentralizaron servicios y equipamiento urbano, se desalojó al comercio informal y se realizaron importantes inversiones en edificios y espacios públicos. Estas estrategias, si bien alentaron la inversión privada y propiciaron un repunte turístico sin precedentes en el centro histórico, generaron también un paulatino pero firme decremento de la población y el incremento del valor tanto de las propiedades y las rentas como de las operaciones de compraventa e inversiones en giros turísticos.

La definición del patrimonio del sitio, sustentada en el Decreto Federal de Zona de Monumentos Históricos, de 1990, comprendió 219 manzanas y 1113 edificaciones, 93\% de las cuales eran de propiedad privada, universo a partir del cual se abordó la identificación de los procesos de conservación y transformación.

El cambio más sensible en el patrimonio edificado privado fue la disminución del uso habitacional, ya que de 99 inmuebles incluidos en el Reglamento para la Conservación del Aspecto Típico y Colonial de la Ciudad de Morelia de 1956, para 1981 - fecha del primer estudio de Ramírez- sólo 54.55\% conservó ese uso, y para el 2007 - fecha del estudio de campo-disminuyó a $28.49 \%$. En este último año los usos preponderantes fueron, por orden decreciente, comercial y oficinas, turismo, así como habitacional y mixto.

En los inmuebles privados, el uso del suelo determina la posibilidad de acceso: restringido, que se puede denominar como privado, o bien libre, que permite calificarlo como público; entre esos extremos, el acceso intermedio en inmuebles privados con uso mixto es libre en determinados espacios, pero restringido en otros. Los cambios en el uso del suelo propiciaron una mayor posibilidad de acceso a este tipo de inmuebles (salvo aclaración en contrario, las siguientes comparaciones corresponden a los años citados arriba, es decir, 1981 y 2007): el acceso libre se incrementó de $1 \%$ a $8 \%$, en tanto que el intermedio creció de $57 \%$ a $62 \%$. La mayor posibilidad de acceso a inmuebles privados, pero condicionada al pago de bienes y servicios que ahí se ofertan, si bien se opone a la naturaleza eminentemente pública de los bienes culturales, se conjuga con el uso comunitario de los espacios públicos en el centro histórico como escenario de múltiples actividades culturales gratuitas, lo que afirma el carácter público del conjunto.

La conservación de las características arquitectónicas originales de un monumento histórico, combinada con 
el buen mantenimiento de sus componentes materiales, significa un estado óptimo. Con este criterio se observó una sensible mejoría del patrimonio edificado privado, ya que los inmuebles en estado óptimo y regular alcanzaron en conjunto casi $94 \%$ de la muestra en el 2007 . No obstante que los inmuebles en pésimo estado disminuyeron, la pérdida de patrimonio se incrementó de $1 \%$ a $4 \%$.

Si bien para 1981 los inmuebles en estado óptimo eran preponderantemente de uso habitacional y mixto, para el 2007 las edificaciones en mejores condiciones fueron las destinadas a hoteles, restaurantes y bares, seguidas de comercios, bancos y oficinas.

Las ineficiencias de la propiedad privada se situaron en: pérdida o alteración de elementos arquitectónicos, registradas en más de $50 \%$ de las edificaciones en el 2007; uso de tecnologías inadecuadas y sobrecarga estructural, así como detrimento del contexto por publicidad comercial inapropiada o falta de mantenimiento en fachadas. No obstante, comparado con los datos de 2001, el deterioro del contexto decreció de un 33\% a un $20 \%$ para el 2007, gracias a la regulación de anuncios comerciales y programas de mantenimiento de fachadas.

Un aspecto relevante es el efecto diferenciado de las políticas aplicadas, en función del tipo de inmueble. En este sentido, es importante aclarar que el Programa Parcial del Centro Histórico 2001 abarca inmuebles históricos listados en el decreto federal de zona de monumentos de 1990, así como edificaciones del siglo Xx consideradas valiosas pese a no estar catalogadas; no obstante, estas construcciones se clasifican en función de sus características espaciales y formales, agrupadas en las categorías de patrimonio monumental, patrimonio relevante, patrimonio tradicional, patrimonio popular y patrimonio del siglo XX.

El patrimonio edificado monumental incluye 34 inmuebles, originalmente de uso religioso y administrativo; sobresalen del conjunto por sus antecedentes históricos,

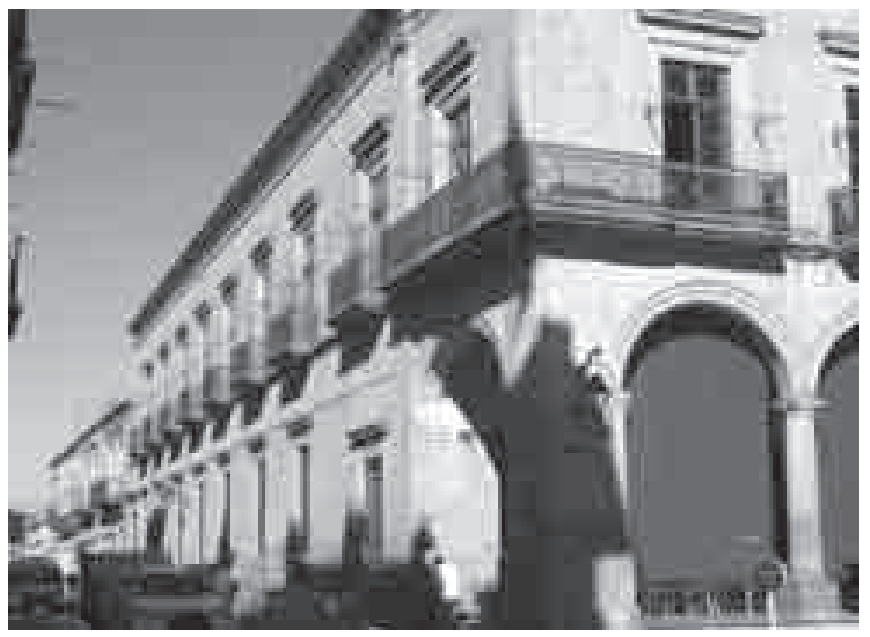

FIGURA 1. Patrimonio edificado relevante, ubicado en el Portal Matamoros, esquina con Allende (Fotografía Eugenio Mercado López, 2007).

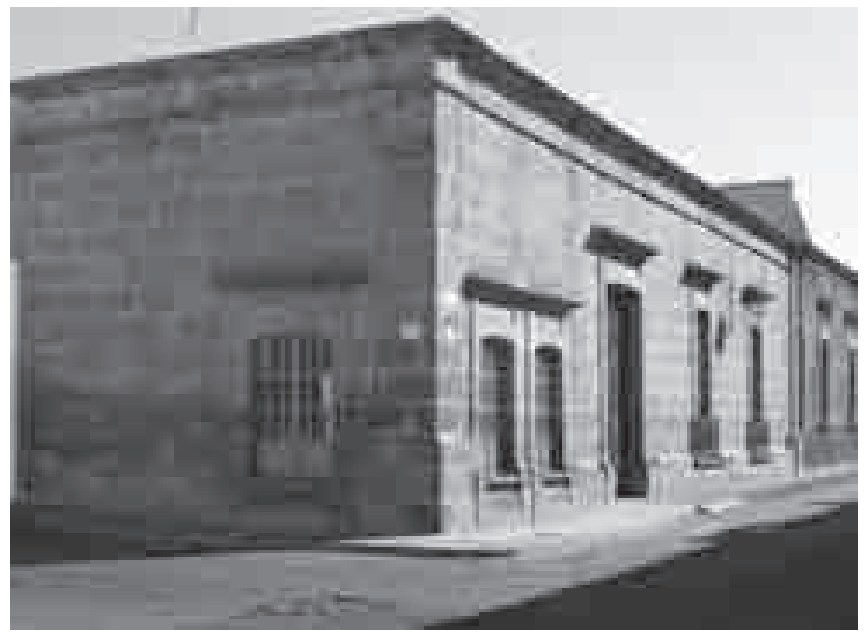

FIGURA 2. Patrimonio tradicional. Vivienda ubicada en la calle Corregidora, esquina con Rayón (Fotografía Eugenio Mercado López, 2007).

calidad arquitectónica y magnitud; todos ellos son de propiedad pública, y su estado de conservación es óptimo en la gran mayoría de los casos.

El patrimonio edificado relevante comprende 70 inmuebles; presenta gran calidad arquitectónica, antecedentes históricos y características estilísticas de gran valor (Figura 1); se ubica, preponderantemente, en las manzanas que rodean a la Plaza de Armas y la Catedral. En este caso hubo un drástico cambio de uso del suelo, ya que en su origen se trataba de edificios de uso habitacional y mixto, y para el año 2007 ninguno conservaba esos usos. La conservación alta y media fue de $50 \%$ de los casos en 1981; para el 2007 se observó un alta conservación en $83 \%$ de los inmuebles, y media en $17 \%$ de ellos. Para el 2007 , no obstante, $14 \%$ se encontraba en restauración, lo cual muestra que hay requerimientos de mantenimiento después de usos más intensivos (aparte de que, previo a su reciclaje, es necesario, asimismo, determinar la capacidad de carga de cada inmueble).

El patrimonio edificado tradicional suma 799 inmuebles; conserva elementos decorativos y estilísticos de la arquitectura relevante, pero con características más modestas; complementa el contexto, y es una transición entre la arquitectura relevante y la popular (Figura 2). Estos inmuebles presentaron una mayor variedad de usos que el patrimonio relevante: para el 2007,30\% de ellos alojaba comercios, oficinas y bancos — porcentaje similar al de los usos turísticos-, así como uso habitacional en $20 \%$ de los casos; asimismo, se observaron usos educativos, culturales, como talleres y bodegas, conventos y sin uso, que en conjunto sumaron $6.50 \%$. De éstos, $54 \%$ mantenían sus características originales, en tanto que el mantenimiento de bueno a regular se observó en más de 90\% de estas edificaciones.

Los patrimonios relevante y tradicional tuvieron una buena conservación, atribuible a la alta capacidad de estos inmuebles para contener nuevos usos -en particu- 


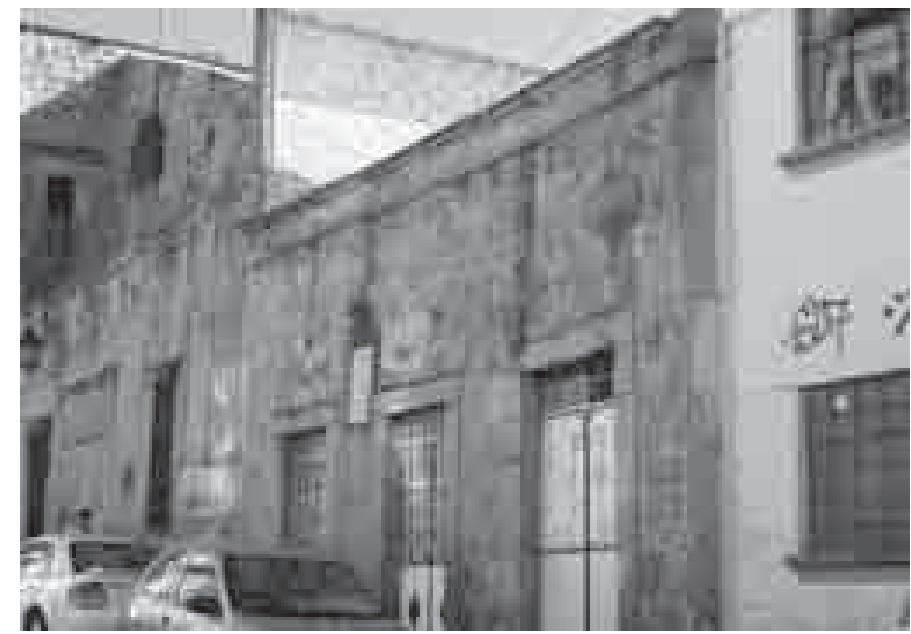

FIGURA 3. Patrimonio edificado popular, ubicado en la calle Matamoros, núm. 63 (Fotografía Eugenio Mercado López, 2007).

lar, al adecuarse para aquellos especializados vinculados al turismo y la cultura-, con lo que se generan recursos económicos para su mantenimiento, resultando beneficiados en el proceso.

En cuanto al patrimonio edificado popular, está compuesto por 520 inmuebles de características modestas, testimonios de la arquitectura vernácula que sirve de acompañamiento al conjunto urbano (Figura 3), en tanto que el patrimonio del siglo Xx lo integran inmuebles que presentan fachadas con características neocoloniales o Art Déco.

El patrimonio edificado popular, de estructuras modestas y superficies de terreno reducidas, así como el patrimonio del siglo XX, de pequeñas dimensiones, conservaron mayoritariamente los usos habitacionales y mixtos, lo cual es atribuible a su escasa capacidad de adaptación a nuevos usos y a la limitada flexibilidad normativa para permitir esas adecuaciones (pese a ello, en sus inmuebles se observaron más modificaciones parciales o totales). En el 90\% de estos inmuebles se registró un uso habitacional en 1981, y de un $70 \%$ para el año 2007; una alta conservación en el 60\% de los casos en 1981, del $20 \%$ en 2001 , y del $40 \%$ en el 2007. Pese a la disminución de inmuebles con mantenimiento deficiente, para este último año de 2007 se observó un $56 \%$ de inmuebles con mantenimiento regular y un $4 \%$ de edificaciones derruidas.

En el estudio de campo 2007 no se identificaron pérdidas de patrimonio edificado relevante; en cambio, en el tradicional, el menoscabo de elementos de su interior se registró en $7 \%$ de los casos. En el patrimonio edificado popular tanto la pérdida total como la de interiores alcanzó $9 \%$. Es decir, este tipo de patrimonio sufrió una mayor transformación y deterioro en el periodo. En este sentido, estudios previos realizados por Ramírez en 1981 y 1985 concluían que el cambio de uso habitacional por comercial u oficinas había sido decisivo en el deterioro y pérdida de las características originales de estos inmuebles, pero la nueva dinámica urbana observada a partir de 1991 tras- tocó ese principio: la evidencia indica que, además del uso público, los usos especializados vinculados al turismo son propicios para la conservación y el rescate de las características originales de las edificaciones, lo cual se refleja en el incremento del valor inmobiliario. El uso habitacional no fue determinante para la conservación de los inmuebles; por el contrario, se observa que en edificios patrimoniales utilizados como viviendas existe un proceso de deterioro más acelerado y alteración de sus características arquitectónicas originales.

Estas afirmaciones se corroboran al observar la localización del patrimonio edificado en buen estado registrado por Ramírez en 1981, que se distribuía equitativamente en el centro histórico; en el Programa Parcial del Centro Histórico 2001, en cambio, se concentra en áreas con usos preponderantemente turísticos y comerciales (Figura 4), en tanto que aquel en mal estado se ubica en los barrios tradicionales, donde los usos habitaciones son preponderantes (Figura 5).

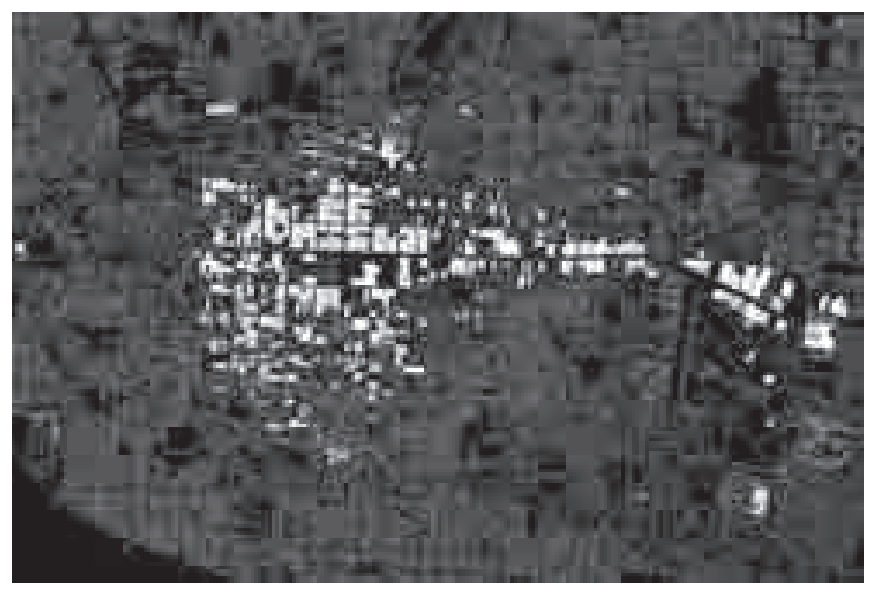

FIGURA 4. Patrimonio edificado en buen estado de conservación 2001. (Imagen elaborada por Eugenio Mercado López a partir del Programa Parcial del Centro Histórico de Morelia, H. Ayuntamiento, 2001).

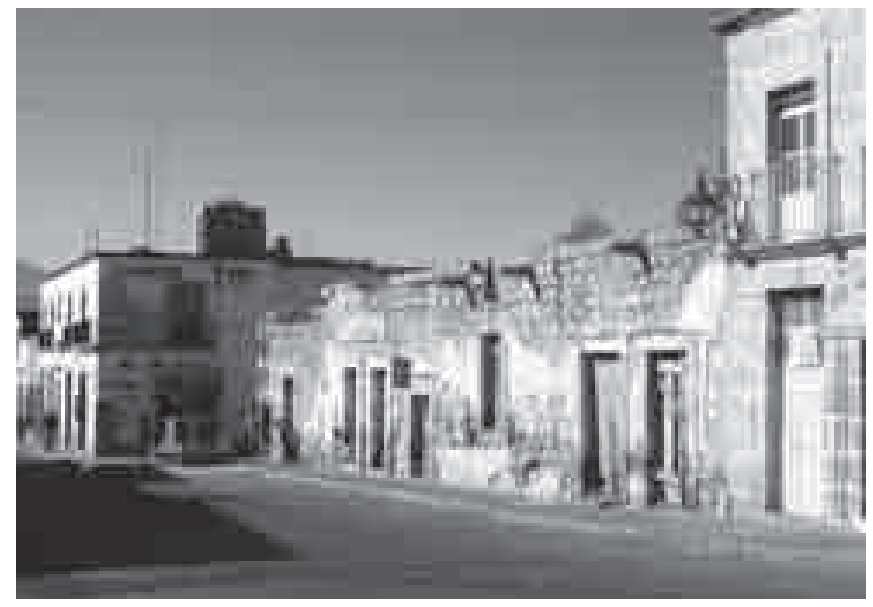

FIGURA 5. Patrimonio edificado en mal estado de conservación. Calle Vicente Santa María. (Fotografía Eugenio Mercado López, 2011). 
Los cambios de uso del suelo, además de que propiciaron la subdivisión de lotes, la apertura de vanos, y la eliminación de muros intermedios para ampliar espacios y dar cabida a actividades comerciales, se encuentran vinculados con fenómenos como el despoblamiento y la modificación sensible en la composición demográfica.

De acuerdo con el Programa Parcial del Centro Histórico vigente, la zona urbana protegida legalmente, denominada centro histórico, está conformada por la zona de monumentos, así como por una más, de amortiguamiento, que lo circunda, que en conjunto presentaron una tasa poblacional negativa de $2.81 \%$ entre 1990 y el 2005; de forma desagregada, la zona de monumentos tuvo un decremento de población de $3.45 \%$, y la de transición registró un crecimiento de $2.17 \%$. De mantenerse esa tendencia, para el 2020 la población del centro histórico habrá disminuido a 23280 habitantes, es decir, la que tuvo el sitio hacia 1880. Por su parte, entre 1990 y 1995 se perdieron 680 viviendas que, de forma desagregada, significaron 721 viviendas menos en la zona de monumentos y construcción de 41 nuevas viviendas en la de transición, es decir, un promedio de 136 viviendas perdidas por año, lo cual era significativo, ya que el crecimiento de la ciudad demandaba 4388 viviendas anuales (Ayuntamiento de Morelia 2001:30).

Los cambios en el uso del suelo, la concentración del patrimonio edificado en buen estado en la parte nuclear del centro histórico y la mayor degradación de inmuebles catalogados en los barrios tradicionales tienen que ver también con las tradicionales concentración de inversiones públicas en la zona central y desatención hacia los antiguos barrios, donde, además, se ubicó equipamiento urbano lesivo para el patrimonio edificado en etapas urbanísticas previas, lo cual motivó la transformación de inmuebles ubicados alrededor de los mercados, hospitales y sedes de educación superior, construidos a lo largo del siglo XX.

En suma, la inclusión del sitio en la Lista del Patrimonio Mundial propició una notoria mejoría en la conservación de espacios y edificios públicos, repunte del turismo, inversiones y creación de empleos en esa actividad, éxito que, sin embargo, no se tradujo en beneficios para el patrimonio edificado más modesto, barrios tradicionales o zonas periféricas del centro histórico, ni para sus habitantes o propietarios, lo cual se refleja en un proceso de despoblamiento paulatino pero sostenido del sitio en las últimas décadas.

\section{Conclusiones}

De acuerdo con lo observado, se puede establecer que el ámbito de lo público que sostiene el concepto del patrimonio cultural incide en el ámbito de lo privado solamente si la valoración social de los bienes culturales puede traducirse en políticas públicas que propicien la vigencia simbólica, física, funcional y económica del patrimonio edificado.

La designación legal de un inmueble privado como monumento histórico o artístico no lo sustrae del mercado inmobiliario, no cambia su naturaleza vinculada a la generación de riqueza ni modifica en esencia el régimen de propiedad, aunque sí limita, sin que el ámbito público asuma directamente su conservación, los derechos de propiedad. De lo anterior deriva el conflicto de intereses implícito en esta categoría del patrimonio cultural, ya que confronta los conceptos de lo público y lo privado, opuestos de origen, y circunscribe la intervención pública a la mera voluntad del propietario en el mercado inmobiliario, con lo que se induce que el uso y el consumo de ese patrimonio sea a través de las políticas públicas.

La conservación del patrimonio edificado responde a varios factores, en tanto que la delimitación de un centro histórico, la selección de inmuebles, las inversiones para la conservación de edificios y espacios públicos, y la gestión turística del patrimonio, son externalidades que, al propiciar un consumo conjunto de actividades especializadas, incrementan el valor económico del patrimonio edificado privado.

Por su parte, la capacidad de los inmuebles para alojar nuevas funciones distintas de las originales genera efectos diferenciados de la actuación pública sobre el patrimonio edificado privado, por lo que, a una menor capacidad funcional de las edificaciones privadas para contener nuevos usos, aun los habitacionales, es necesaria una mayor intervención pública para lograr la permanencia de las características originales. Las edificaciones más modestas - a pesar de que conserven un uso habitacional- están destinadas a desaparecer, por su limitada capacidad para contener actividades propias de la vida actual; como la valoración social de este patrimonio es escasa, no es capaz de transmitir un valor simbólico, funcional o económico que propicie su permanencia, la cual radica en gran parte en asignarle funciones específicas y adecuarlas a nuevos requerimientos: entre otros, como vivienda para la tercera edad, para parejas jóvenes, estudiantes, creadores artísticos, o de alquiler de bajo costo.

No obstante que la decisión del propietario acerca de conservar o no un inmueble puede ser alterada por condiciones externas a los bienes, como son las políticas públicas, en el deterioro del patrimonio edificado privado se observa desconocimiento, o deficiente apreciación, de los propietarios de las ventajas de aprovechar los incentivos fiscales, como, por ejemplo, el incremento del valor inmobiliario o la ganancia por la venta de un inmueble que conserve sus características originales; por lo que toca al ámbito gubernamental, se advierte una deficiente difusión, orientación y aplicación de los incentivos fiscales, así como de los apoyos técnicos y legales existentes en favor de la conservación de los inmuebles de propiedad privada. 
Pese a que en el proceso de rescate del Centro Histórico de Morelia se han incorporado al ámbito de las políticas públicas diversas estrategias y acciones — tomadas de experiencias nacionales e internacionales, conjugando una fuerte tradición local en favor de la conservación-, éstas carecen de un enfoque integral, al centrarse en inversiones aplicadas en espacios y edificios relevantes, desatendiendo tanto la actualización y el perfeccionamiento de la legislación como la difusión de los incentivos fiscales, la asesoría y el apoyo a los propietarios, la incorporación del patrimonio reciente en los catálogos de monumentos o el cuidado de barrios tradicionales y zonas periféricas del centro histórico (Mercado 2008). En particular se observa una falta de reconocimiento de la naturaleza económica del patrimonio edificado de propiedad privada y escasa comprensión de su comportamiento como objeto de consumo.

Los conceptos vigentes en torno del patrimonio edificado, así como la ausencia de un marco teórico que sustente la construcción de políticas públicas, han privilegiado el uso de ese patrimonio en actividades especializadas que soslayan las formas de vida que en su momento les dieron origen y que en la actualidad hacen posible su permanencia. Con ello se ha propiciado no sólo la desaparición de las estructuras arquitectónicas que no se adaptan a los requerimientos turísticos, sino también despoblamiento y segregación de los barrios tradicionales, de modo que al ir desapareciendo los valores culturales y formas de vida locales, que son la principal motivación de visita para el turista cultural contemporáneo, se ha puesto en riesgo la posibilidad de sostener el aprovechamiento del conjunto.

La ausencia de apoyos e incentivos para conservar a los habitantes originales y atraer otros nuevos, más el incremento del valor del suelo inducido por las actuaciones públicas y privadas, propician que los propietarios vendan o abandonen sus inmuebles, con lo que se genera tercerización y segregación socioespacial de los habitantes que permanecen en el sitio. Esto, aunado a la pérdida de funciones diversificadas en aras de la especialización turística de algunas zonas, cuestiona seriamente el actual modelo de conservación y aprovechamiento de estos sitios.

En suma, el proceso de conservación del patrimonio edificado, incluso de aquel de propiedad privada, tiene viabilidad como modelo de desarrollo urbano solamente si se sustenta en beneficios colectivos y cumple con la función social que se le ha conferido como palanca del desarrollo regional y en el combate a la pobreza urbana, lo cual justifica no sólo la intervención del Estado, sino también las altas inversiones públicas que se requieren.

\section{Referencias}

Ayuntamiento de Morelia

2001 Programa Parcial del Centro Histórico de Morelia, Morelia.

Azuela, Antonio

1989 La ciudad, la propiedad privada y el derecho, México, El Colegio de México.

Debray, Regis

1999 L'Abus monumental ? Entretiens du Patrimoine, París, Fayard.

Hernández, Julia

2006 La ciudad y su análisis intra-urbano: la localización de actividades económicas y el futuro de los centros, documento disponible en [http://www.eumed.net/ce/2006/jha-ciu. htm], consultado en enero del 2010.

INAH

2003 Catálogo de monumentos históricos del municipio de Morelia, Morelia.

Krebs, Magdalena y Klaus Schmidt-Hebbel

2002 "Patrimonio cultural: aspectos económicos y políticas de protección", Perspectivas, 2 (2): 209-223.

Mason, Randy (ed.)

1999 Economics and Heritage Conservation: A Meeting Organized by the Getty Conservation Institute, diciembre de 1998, Los Ángeles, J. Paul Getty Trust.

Mercado, Eugenio

2008 Políticas públicas en el Centro Histórico de Morelia: Éxito turístico y efectos contradictorios en el patrimonio edificado, documento disponible en [http://redalyc.uaemex.mx/ src/inicio/ArtPdfRed.jsp?iCve=94814746005], consultado en noviembre del 2009.

Moisset de Espanés, Luis

1966 Notas sobre el concepto de límites de la propiedad en el derecho comparado, documento disponible en [http:// www.acaderc.org.ar/doctrina/articulos/artnotasconceptolimitepropiedad], consultado en diciembre del 2009.

Olivé, Julio César

1988 INAH, una historia, México, INAH.

Ramírez, Esperanza

1981 Catálogo de construcciones artísticas, civiles y religiosas de Morelia, Morelia, UMSNH/Fonapas.

1985 Morelia en el espacio y en el tiempo. Defensa del patrimonio histórico y arquitectónico de la ciudad, Morelia, Gobierno del Estado de Michoacán.

Rivas, Juan de las

1998 "La reutilización del espacio. Sobre las condiciones del proyecto de ciudad histórica", en Ignacio Represa (coord.), Restauración arquitectónica, Valladolid, Universidad de VaIladolid, 209-218.

Rosas, Ana

1996 "La exploración antropológica sobre la conservación, apreciación y usos del patrimonio cultural urbano", en Amparo Sevilla y Miguel Ángel Aguilar (coords.), Estudios recientes sobre cultura urbana en México, México, INAH/Plaza y Valdés, 65-88. 


\section{Resumen}

Las características del patrimonio edificado de propiedad privada, cuyo deterioro es un problema que afecta a diversas ciudades de México, han justificado, por su importancia como elementos de identidad y cohesión social, y como generadores de beneficios económicos, que el Estado intervenga en la conservación de sus inmuebles, proceso que se inscribe en la dicotomía de lo público y lo privado, al incluir bienes inmersos en el mercado inmobiliario que a la vez son considerados un bien público.

Tanto los escasos estudios acerca del patrimonio edificado de propiedad privada como los limitados efectos de las políticas públicas instrumentadas para su protección han creado un vacío que el presente trabajo, con la aportación de datos que contribuyan a conocer los problemas urbanos vinculados a la conservación del patrimonio edificado y de los centros históricos del país — particularmente el de Morelia, Michoacán—, pretende ayudar a subsanar.

\section{Palabras clave}

Patrimonio edificado, propiedad privada, conservación.

\section{Abstract}

The deterioration of privately owned property considered part of the built heritage environment is a problem that affects various Mexican cities. The preservation process of buildings, particularly privately owned property, is inscribed in the dichotomy of the public and the private, as these edifices, while being part of the general real estate market, are also considered public goods. These characteristics, augmented by the importance of buildings as contributors of identity and social cohesion, have justified state intervention for their protection and continued use. This research focuses on examining privately owned heritage property as well as the effects of public policies implemented for its protection in Mexico, thus contributing to the knowledge of urban problems related to heritage preservation in the country's historic centres and filling a scholarship gap.

\section{Keywords}

Built heritage, private property, preservation. 